\title{
Bone marrow aspiration in a patient with systemic microsporidium
}

\author{
Ximena Gomez ${ }^{1}$, Jorge Castillo², and Marco Gomez ${ }^{3}$ \\ ${ }^{1}$ Universidad Peruana de Ciencias Aplicadas \\ ${ }^{2}$ Dana-Farber Cancer Institute \\ ${ }^{3}$ Clínica Centenario Peruano Japonesa
}

December 14, 2021

\begin{abstract}
A 34-year-old female presented with several weeks of fever, fatigue, weight loss, abdominal pain and hemoptysis. PE revealed moderate pallor, RUQ pain, mild dyspnea, conjunctival injection and hepatomegaly. The CBC showed anemia, mild leukocytosis, hypoalbuminemia, hypertransaminasemia, presence of nucleated red blood cells. Microsporidium was found in BMA.
\end{abstract}

\section{Hosted file}

Final Bloodwork Microsporidium .pdf available at https://authorea.com/users/451157/articles/ 549382-bone-marrow-aspiration-in-a-patient-with-systemic-microsporidium 


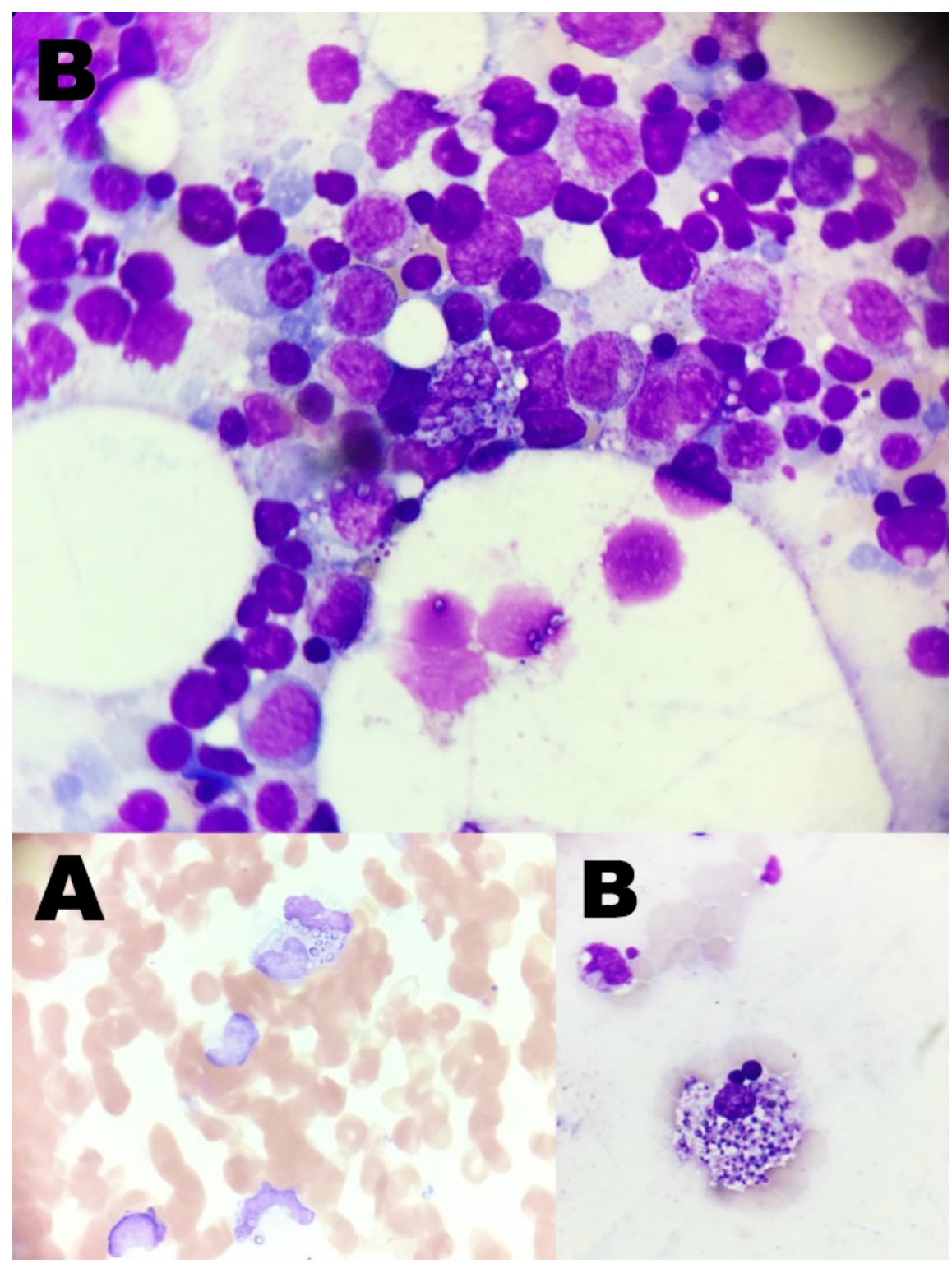

